\title{
Effect of End Tidal Carbondioxide concentration on different phases of menstrual cycle in subjects suffering with Premenstrual syndrome
}

\author{
Chandra selvi .E ${ }^{1}$, Sai Kumar .P ${ }^{2}$, Hansa Jeyakumar ${ }^{3}$, Kuppu Rao .K . V \\ ${ }^{1,2,3}$ Depatment of physiology, Sree Balaji Medical College,Bharat University, India \\ ${ }^{4}$ Tuberculosis Research Centre, ICMR-India
}

\begin{abstract}
Background: Previous studies have been reported that about $80 \%$ of women experience premenstrual syndrome (PMS) during luteal phase of menstrual cycle. Normally menstruating women show hypocapnia followed by increased ventilation due to increased progesterone during the luteal phase compared follicular phase. As specific reason for PMS has not still been proved, various theories have been revealed and hence for PMS specific treatment is still not available. Aim: To assess the effect of End tidal carbondioxide concentration on different phases of menstrual cycle in subjects suffering from PMS. Material and methods: We recruited 50 female volunteers aged around $26 \pm 5$ yrs with normal menstrual cycle and complaint of PMS. End tidal carbon dioxide $\left(\mathrm{ETCO}_{2}\right)$ and respiration rate was noninvasively monitored by using capnometer during the follicular phase (days $6^{\text {th }}$ or $7^{\text {th }}$ ), the luteal phase (days $25^{\text {th }}$ or $26^{\text {th }}$ ) and $2^{\text {nd }}$ day of menstrual phase. Results: Respiratory rate and heart rate were significantly increased in luteal phase when compared to follicular and menstrual phase. The highlighted result of our study was lower $\mathrm{ETCO}_{2}$ in luteal phase than other two phases. Conclusion: Reduced $\mathrm{ETCO}_{2}$ (hypocapnia) due hyperventilation in luteal phase may alter the functions of chemo sensitive neurons which may be the reason for PMS. In women with many kinds of stress the psychological symptoms may gradually be disappeared with normalization of breathing habits during luteal phase of menstrual cycle.
\end{abstract}

Key words: Premenstrual syndrome, menstrual cycle, End tidal carbondioxide, Hypocapnia, Hyperventilation

\section{Introduction}

End tidal carbon dioxide $\left(\mathrm{ETCO}_{2}\right)$ is the amount of $\mathrm{CO}_{2}$ expired at the end of quiet normal breathing. The amount of $\mathrm{ETCO}_{2}$ is equal to the partial pressure of $\mathrm{CO}_{2}\left(\mathrm{PaCO}_{2}\right)$ in arterial blood. $\mathrm{ETCO}_{2}$ has been used as a non-invasive estimate of $\mathrm{PaCO} 2$ (1). Factors (neural and humoral) which decrease ventilation will increase $\mathrm{PaCO}_{2}$ concentration (Hypercapnia) and factors which increase ventilation will decrease $\mathrm{PaCO}_{2}$ concentration (hypocapnia). Among the physiological factors progesterone plays an important role on increase in minute ventilation (hyperventilation) and oxygen consumption which has been highlighted by many authors (2).

However the physiological effects of hypocapnia followed by the hyperventilation during luteal phase is least bothered.

During the reproductive life every woman experiences hyperventilatory syndrome (premenstrual syndrome PMS) a mood disorder specific to the luteal phase of the menstrual cycle. Schruers, et al (3) have suggested that respiratory symptoms are among the most common complaints in patients with panic disorder and are often present in spontaneous panic attacks. Amount of $\mathrm{CO} 2$ and lactate act as respiratory stimulants, have been encouraged much research into the relationship between panic disorder and respiratory physiology as a potential clue for understanding panic disorder.

Mora, et al (4) studied the breathing rate and PCO2 in end-tidal air in controls and in patients with endogenous depression, with neurotic depression, and with schizophrenia. They revealed hyperventilation and hypocapnia in neurotic depression and explained the small chemical differences such as alterations in $\mathrm{pH}$ and other variables in these clinical entities.

Tweeddale, et al (5) suggested that in behavioural breathlessness, breathing retraining is of benefit, not only in restoring more normal patterns of breathing but also in reducing anxiety, particularly in patients with the complication of depression. Several studies reveal the role of female sex hormones on cardiovascular and respiratory changes in women especially during the premenstrual phase. Hence this study was designed to know the effect of hormonal and ventilatory changes on psychological activities during different phases of menstrual cycle. 


\section{Materials and methods:}

Study population: We recruited 50 female volunteers aged 26 \pm 5 (21-31yrs) of Sree Balaji Medical College \& Hospital for the study. Study design was explained and informed consent was obtained from each subject.

\section{Inclusion criteria:}

1. Normal BMI

2. Regular menstrual cycle ( $26-34$ days)

3. Normal hematological parameters

4. Normal pulmonary function tests

5. Normal Blood pressure

6. Subjects with psychological symptoms

\section{Exclusion criteria:}

1. Obesity

2. Irregular menstrual cycle of 35 days

3. History of diabetes mellitus,

4. Hypertension,

5. Other endocrine disorders,

6. History of syncopal attacks

Experiments were performed in both Department of Physiology and Anesthesiology Sree Balaji Medical College and Hospital with the ethical committee permission.

Protocol: The subjects were studied on at least three occasions, once during the follicular phase (days $6^{\text {th }}$ or $7^{\text {th }}$ ) and at least once during the luteal phase of the cycle (days $25^{\text {th }}$ or $26^{\text {th }}$ ) and during menstrual phase. The average day (absolute) on which the women were studied during the follicular phase was day $7^{\text {th }}$ of the menstrual cycle, and the average day on which the study was performed during the luteal phase was day $25^{\text {th }}$ and $2^{\text {nd }}$ day of menstrual cycle. All tests were performed at the same time of day (6).

\section{Parameters measured:}

End tidal carbon dioxide $\left(\mathrm{ETCO}_{2}\right)$ and respiration rate was noninvasively monitored by using capnometer. Mainstream $\mathrm{CO}_{2}$ Sensor was attached to an airway adapter that connected to a mask. Subjects were instructed to breath normally into the adapter. The moniter displayed the numeric $\mathrm{ETCO}_{2}$ value in units of $\mathrm{mmHg}$ and number of breaths per minute, labeled "RR" for respiration rate/min in a capnogram waveform. Arterial oxyhemoglobin saturation $\left(\mathrm{SaO}_{2}\right)$ and heart rate were measured transcutaneously with a pulse oximeter.

All values were expressed as means \pm std for the group .Within-group comparisons between the follicular and luteal phases were made with a paired Student's $t$-test. A two-tailed $P$ value, 0.05 was considered significant. $P$ values. 0.1 are reported as not significant.

\section{Results:}

Table I Characteristic features of the subjects

\begin{tabular}{|c|c|}
\hline Age $($ years $)$ & $21 \pm 2$ \\
\hline Weight $(\mathrm{kg})$ & $52 \pm 5$ \\
\hline Height $(\mathrm{cm})$ & $154 \pm 7$ \\
\hline Body mass index $\left(\mathrm{kg} / \mathrm{m}^{2}\right)$ & $26 \pm 1$ \\
\hline No of Subjects & 50 \\
\hline
\end{tabular}

With suitable criteria as characters given in Table I including normal Body mass index (BMI) and age a total of 50 female volunteers were recruited in our study. Results are summarized in Table II. Heart rate in the follicular phase $(73 \pm 6 / \mathrm{min})$ was significantly reduced when compared to luteal phase $(94 \pm 9 / \mathrm{min})$ and menstrual phase $(82 \pm 3 / \mathrm{min})$ but values were not statistically significant. Respiratory rate was statistically found to be more in luteal phase $(24 \pm 4 / \mathrm{min})$ when compared to follicular and menstrual phases $16 \pm 2 / \mathrm{min}, 19$ $\pm 3 / \mathrm{min}$ respectively. $\mathrm{ETCO}_{2}$ level was significantly lower in luteal phase $(29 \pm 2 \mathrm{~mm} \mathrm{Hg})$ than follicular $(41 \pm$ $2 \mathrm{~mm} \mathrm{Hg})$ and menstrual cycle $(39 \pm 3 \mathrm{~mm} \mathrm{Hg})$. 
Effect of End Tidal Carbondioxide concentration on different phases of menstrual cycle in subjects

Table II Parameters variation in different phases of menstrual cycle

\begin{tabular}{|c|c|c|c|}
\hline Menstrual cycle & $\begin{array}{c}\text { End Tidal CO2(mmHg) } \\
\text { Mean } \pm \text { Std }\end{array}$ & $\begin{array}{c}\text { (Respiratory Rate)/min } \\
\text { Mean } \pm \text { Std }\end{array}$ & $\begin{array}{c}\text { (Heart Rate)/min } \\
\text { Mean } \pm \text { Std }\end{array}$ \\
\hline Menstrual phase & $39 \pm 3$ & $19 \pm 3$ & $82 \pm 3$ \\
\hline Follicular phase & $41 \pm 2$ & $16 \pm 2$ & $73 \pm 6$ \\
\hline Luteal phase & $29 \pm 3^{*}$ & $24 \pm 4^{*}$ & $94 \pm 9^{*}$ \\
\hline
\end{tabular}

All values are expressed in Mean \pm Std $*$ indicate $<0.05$ show statistical significant

Fig-1 Heart Rate changes in different phases of menstrual cycle

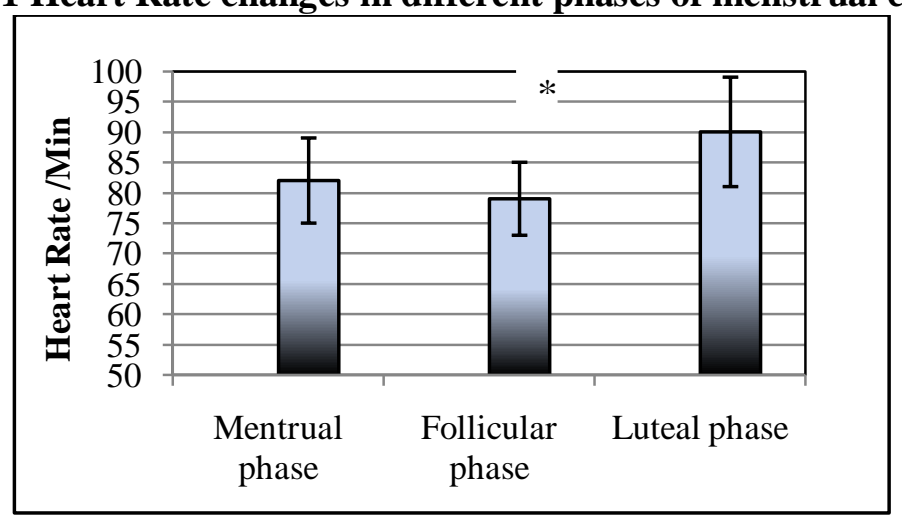

Fig II Respiratory Rate changes in different phases of menstrual cycle

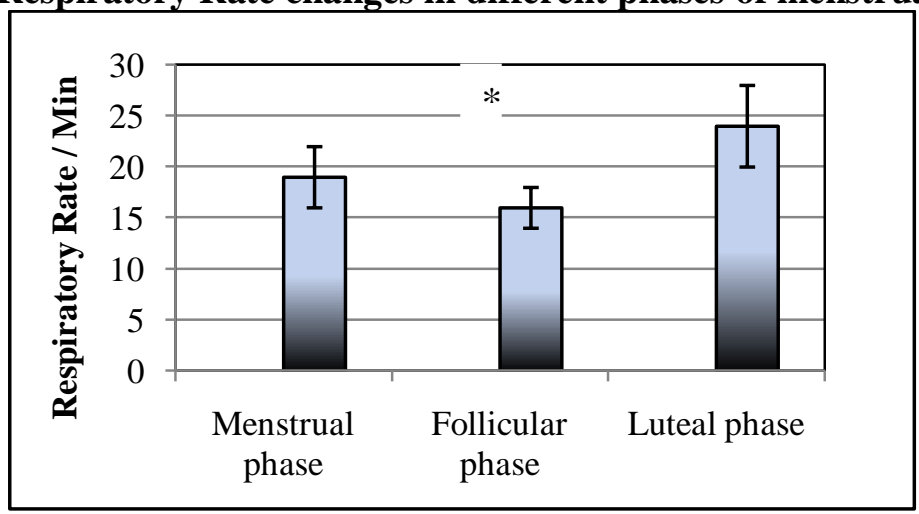

Fig III End Tidal $\mathrm{CO}_{2}$ changes in different phases of menstrual cycle

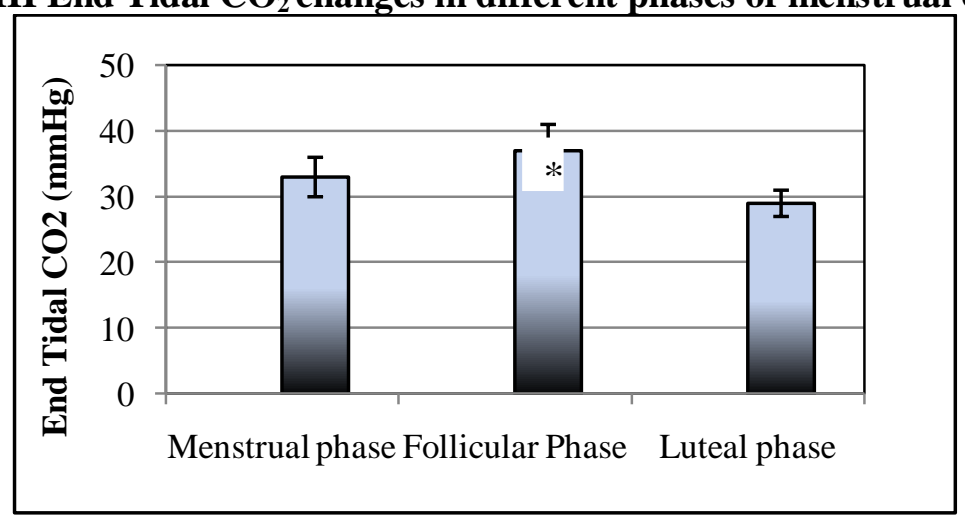

\section{Discussion}

The premenstrual phase was taken as late luteal (LL) phase and postmenstrual phase as an early follicular (EL) phase of menstrual cycle by earlier workers (6) and a large number of studies in relation to the menstrual cycle were carried out which proved that hormonal levels never change during the particular days of normal menstrual cycle.

This study has demonstrated the increased respiratory rate during the luteal phase of the menstrual cycle when compared to follicular phase. Earlier studies have been revealed that an increase in progesterone 
secretion was a possible cause for the hyperventilation in the luteal phase (7). Delaunois et al(8) used Progesterone as the ventilatory stimulant in the condition like breathing disorders because the level of circulating progesterone is known to increase ventilation. Progesterone stimulates respiration centrally through a steroid receptor-mediated mechanism. Further more if the progesterone is directly injected into the region of nucleus tractus solitarius, an area in the medulla oblongata increase phrenic nerve activity thus enhance respiration.

Though progesterone has the beneficial role on respiration by increasing the oxygen consumption, the fate of hyperventilation such as hypocapnia involves misattribution and anxiety $(9,10)$. In the present study luteal phase was taken as premenstrual phase and the signs and symptoms related to the phase was premenstrual syndrome, which involves physical symptoms like bloating, headache along with psychological and behavioral changes like irritability, depression, and fatigue. The most highlighted factor in our study was reduced End tidal $\mathrm{CO}_{2}$ in luteal phase when compared to other two phases. Acetazolamide a carbonic anhydrase inhibitor administration in patients with panic disorder was believed to increase brain $\mathrm{pCO} 2$ without stimulating peripheral chemoreceptors and did not provoke panic, it was suggested that hypocapnia has been involved in experimental panic (11).

In pathophysiological model for panic disorder when voluntary hyperventilation was induced by sodium lactate symptoms like decrease in $\mathrm{pCO} 2$ that overlap with panic (e.g., dizziness, paresthesia), were observed by Lum, 1987 (12). Interestingly, in contrast to our study Wilhelm, et al., 2001 (13)compared healthy subjects and patients with anxiety disorders, patients with panic disorder showed a slower physiological (i.e., pCO2) and psychological recovery after voluntary hyperventilation. Friedman, et al., 2006 (14) observed hyperventilation such as the increased alkalotic buffering capacity in patients with panic disorder due to lactate accumulation and slight acidosis found in healthy subjects during recovery.

The neurons that respond to $\mathrm{CO} 2$ and $\mathrm{H}^{+}$drive the cascade of events leading to panic are likely to be a complex system which involve many brain sites (15). As respiratory symptoms are common complaints in panic (16), particularly in spontaneous panic attacks, some overlap must exist between chemosensitive neurons that serve respiration and those that elicit panic. For example, the locus coeruleus and Hypothalamus which are brain locations with $\mathrm{CO} 2$ and $\mathrm{H}^{+}$sensitive neurons that most likely serve both respiration and panic responses (17). The amygdala, another brain structure implicated in defensive behaviour, is also known to have neurons that monitor concentration of $\mathrm{CO} 2$ and $\mathrm{H}^{+}$.

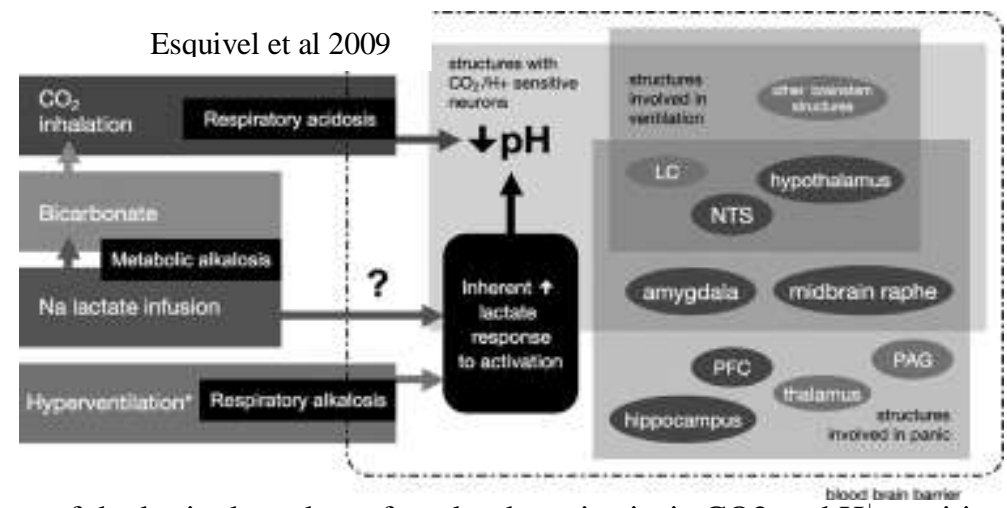

Many regions of the brain have been found to have intrinsic $\mathrm{CO} 2$ and $\mathrm{H}^{+}$sensitive neurons, such as the nucleus tractus solitarii, the medullary raphe, the locus coeruleus, the nucleus ambiguous, midbrain raphe neurons and the ventrolateral medulla, play a role in ventilation (18). Severson, et al. 2003 (19) have proposed that midbrain serotonergic neurons with rostral projections, in contrast to those in medullar 5-HT neurons projecting caudally to serve respiration, may be implicated in other behaviours that are also related to respiratory acidosis, such as increased arousal and panic. Orexin hypothalamic neurons, which have a role in the upregulation of arousal and ventilation, are activated by decreases in $\mathrm{pH}$ in a way similar to classical chemosensitive neurons.

Finally our study showed increased heart rate in luteal phase when compared to other two phases. A lower level of carbon dioxide triggers an increase in production of hormones such as adrenaline. These hormones help to stimulate the body and increase the heart rate, breathing etc. Catecholamine sensitivity decreases in hypercapnic acidosis and increases in hypocapnic alkalosis. These changes in catecholamine level and sensitivity affect heart. Lower intracellular $\mathrm{pH}$ is the trigger for noradrenaline release from the locus coeruleus during panic attacks (20). The changes in sympathetic activity during premenstrual phase are associated with tension and anxiety (21). 


\section{Conclusion}

The study population complaint of psychological symptoms during premenstrual phase, and also the significant reduction in $\mathrm{PETCO}_{2}$ proved, the role of hypocapnia due to progesterone on cardio respiratory and chemo sensitive neurons. In women with many kinds of stress the psychological symptoms may gradually be disappeared with normalization of breathing habits during luteal phase of menstrual cycle. Further study is needed to find the exact correlation between $\mathrm{ETCO}_{2}$ and hormonal imbalance to prove the significant fluctuation in female reproductive cycles.

\section{References}

[1] Benallal H, Busso T. Analysis of end-tidal and arterial PCO2 gradients using a breathing model. Eur J Appl Physiol 2000; 83:4028.

[2] Das TK. Effects of the menstrual cycle on timing and depth of breathing at rest. Indian J Physiol Pharmacol.1998; 42:498-502.

[3] Schruers, KRJ, van de Mortel, H, Overbeek, T, Griez, E. Symptom profiles of natural and laboratory panic attacks. Acta Neuropsychiatrica.2004; 16: 101-106.

[4] Mora JD, Grant L, Kenyon P, Patel MK, Jenner FA. Respiratory ventilation and carbon dioxide levels in syndromes of depression. Br J Psychiatry. 1976;129:457-64.

[5] Tweeddale PM, Rowbottom I, McHardy GJ. Breathing retraining: effect on anxiety and depression scores in behavioural breathlessness. J Psychosom Res. 1994 ;38:11-21.

[6] Ashwini N. Nilekar, Vaishali V. Patil, Samir Kulkarn, Mangala Vatve Autonomic function tests during pre and post menstrual phases in young women Pravara Med Rev 2011; 6:24-30.

[7] Rajesh CS, Gupta P, and Vaney N. Status of pulmonary function tests in adolescent females of Delhi. Indian J Physiol Pharmacol 44:442-448, 2000.

[8] Delaunois L, Delwiche JP, Lulling J. Effect of medroxyprogesterone on ventilatory control and pulmonary gas exchange in chronic obstructive patients. Respiration. 1985; 47: $107-113$.

[9] Willium N.Gardner, MB,BS. The pathophysiology of hyperventilation disorder. Chest 1996; 109: $516-34$.

[10] von Euler, C. (1983) J. Appl. Physiol. Respir. Environ. Exercise Physiol. 55, 1647-1659.

[11] Gorman, JM, Papp, LA, Coplan, J, Martinez, J, Liebowitz, MR, Klein, DF (1993) The effect of acetazolamide on ventilation in panic disorder patients. Am J Psychiatry 150: 1480-1484.

[12] Lum, LC (1987) Hyperventilation syndromes in medicine and psychiatry:a review. J R Soc Med 80: $229-231$.

[13] Wilhelm, FH, Gerlach, AL, Roth, WT. Slow recovery from voluntary hyperventilation in panic disorder. Psychosom Med.2001; 63:638-649.

[14] Friedman, SD, Mathis, CM, Hayes, C, Renshaw, P, Dager, SR Brain pH response to hyperventilation in panic disorder: preliminary evidence for altered acid-base regulation. Am J Psychiatry. 2006;163: 710-715.

[15] Esquivel, G, Schruers, K, Griez, E (2008) Experimental models: panic and fear. In: Blanchard, RJ, Griebel, G, Nutt, DJ (eds), Handbook of Anxiety and Fear. Elsevier BV, Amsterdam, pp. 413-435.

[16] Colasanti, A, Salamon, E, Schruers, K, van Diest, R, van Duinen, M, Griez, EJ Carbon dioxide-induced emotion and respiratory symptoms in healthy volunteers. Neuropsychopharmacology.2008; 33: 3103-3110.

[17] Williams, RH, Jensen, LT, Verkhratsky, A, Fugger, L, Burdakov, D Control of hypothalamic orexin neurons by acid and CO2. Proc Natl Acad Sci U S A.2007; 104: 10685-10690.

[18] Putnam, RW, Filosa, JA, Ritucci, NA (Cellular mechanisms involved in CO(2) and acid signaling in chemosensitive neurons. Am J Physiol Cell Physiol 2004;287: 1493-1526.

[19] Severson, CA, Wang, W, Pieribone, VA, Dohle, CI, Richerson, GB Midbrain serotonergic neurons are central pH chemoreceptors. Nat Neurosci. 2003; 6:1139-1140.

[20] Andras Sikter, Ede Frecska, Ivan Mario Braun, Xenia Gonda, Zoltan Rihmer. The role of hyperventilation- hypocapnia in the pathomechanism of panic disorder. Rev Bras Psiquiatr.2007.

[21] Sheila R Pai1, Prajna PL, and Urban J.A. D`Souza.A correlative study on blood pressure and lung function profiles during different phases of menstrual cycle among indian populationthai journal of physiological sciences. 2004; 17:30 - 34 